\title{
Monochorionic monoamniotic live twin ectopic pregnancy: a rarity
}

\author{
Vandana Dhama*, Sonam Gupta
}

Department of Obstetrics and Gynecology, Lala Lajpat Rai Medical College, Meerut, Uttar Pradesh, India

Received: 06 December 2019

Accepted: 03 January 2020

\section{*Correspondence:}

Dr. Vandana Dhama,

E-mail: vandanallrm@yahoo.com

Copyright: $\odot$ the author(s), publisher and licensee Medip Academy. This is an open-access article distributed under the terms of the Creative Commons Attribution Non-Commercial License, which permits unrestricted non-commercial use, distribution, and reproduction in any medium, provided the original work is properly cited.

\section{ABSTRACT}

The incidence of unilateral live twin ectopic pregnancy is approximately 1:1,25,000 but increased in last few decades due to increased use of fertility drugs for ovulation induction, superovulation and assisted reproductive technology. It is also associated with increased incidence of pelvic inflammatory diseases. Patient was 30 years old G3P2L2 who presented to OPD of this LLRM medical college, Meerut with complain of amenorrhoea of two and half months. Pelvic examination revealed tenderness in lower abdomen, left adnexal fullness and tenderness without any bleeding. On USG, left adnexal monochorionic monoamniotic ectopic twins with normal cardiac activity. Exploratory laparotomy followed by left sided salpingectomy was done and patient was discharged with satisfactory condition. This is a very rare case and PID is also among risk factors and may also cause twin ectopic pregnancy.

Keywords: Ectopic, Monochorionic, Monoamniotic, Pregnancy, Pelvic inflammatory disease, Twin, Tubal

\section{INTRODUCTION}

Ectopic pregnancy is a pregnancy in which the developing blastocyst becomes implanted at a site other than the endometrium of the uterine cavity. The most common extrauterine location is the fallopian tube, which accounts for 96 percent of all ectopic gestations. ${ }^{1}$ The major cause of ectopic pregnancy is disruption of normal tubal anatomy from factors such as infection, surgery, congenital anomalies or tumors. Anatomic distortion can be accompanied by functional impairment due to damaged ciliary activity. The highest risk is associated with a history of prior ectopic pregnancy or tubal surgery. ${ }^{2,3}$ The rising incidence of ectopic pregnancy is strongly associated with an increased incidence of pelvic inflammatory disease (PID). ${ }^{4}$ Women with a history of PID have an approximately threefold increased risk of ectopic pregnancy. ${ }^{3,5}$

\section{CASE REPORT}

Patient was 30 years old housewife G3P2L2 married for last 6 years who presented to OPD following $2^{1 / 2}$ months amenorrhea. Her present conception was spontaneous and previous two normal deliveries without any complication. She confirmed her pregnancy at home by UPT test. There is no history of pain in abdomen, bleeding $\mathrm{p} / \mathrm{v}$ and vomiting. Patient gave history of recurrent episodes of pelvic inflammatory disease and taken treatment for the same. She gave no H/o Infertility, use of fertility drugsovulation induction drugs, pelvic surgery, use of IUCD, hormonal contraceptive, induced abortion, previous ectopic pregnancy, T.B. or any other chronic disease. Her last menstrual period were $2 \frac{1}{2}$ months back and her previous menstrual cycle were regular and of normal duration of 28 to 30 days. There was no history of use of any IUCD, Hormonal drug for contraception. She had used only Barrier method for contraception. Patient was non-smoker, non-alcoholic, vegetarian by diet. Patient was taking around $2500 \mathrm{Kcal} / \mathrm{day}$. She was carrying an ultrasound which was dated 2 days back when she came to OPD, which showed an ill-defined heterogeneous cystic lesion in left adnexa having single gestational sac measuring $(4 \times 1.5 \times 2.7 \mathrm{~cm})$ of corresponding to 7 week 4 days (Figure1). Two foetal poles were seen in a single gestational sac with foetus $1 \mathrm{CRL}=2.2 \mathrm{~cm}$ corresponding 
to 8 weeks with $\mathrm{FHR}=137 \mathrm{bpm}$ and foetus $2 \mathrm{CRL}=2.1$ $\mathrm{cm}$ corresponding to 7 weeks with FHR $=164 \mathrm{bpm}$. Normal cardiac activity were seen in both foetus. The uterine cavity was empty, free fluid seen in pouch of Douglas (Figure 2) USG was suggestive of left adnexal live monochorionic monoamniotic ectopic twins. On general examination, patient was stable, Pallor was present with pulse 96/min, BP 108/70 mmHg. Tenderness was present in lower abdomen, no guarding felt, no mass palpable. On Per speculum examination, fowl smelling discharge present. On Bi manual examination, uterus was retroverted, bulky, left adnexal fullness and tenderness present and no bleeding was seen. Normal laboratory examination revealed hemoglobin of $6 \mathrm{~g} / \mathrm{dl}$ and beta HCG level $7201 \mathrm{IU} / \mathrm{L}$. In view of the ultrasound findings, the patient underwent Exploratory laparotomy. Intraoperatively, geatation sac was seen in ampullary part of left side of fallopian tube (Figure 3). After which, leftsided salpingectomy was performed (Figure 4). Right tube and right ovary were seen normal. Peripheral adhesions of parietal peritoneum to the liver were also seen (Fitz Hugh-Curtis syndrome). Post-operative recovery was good.

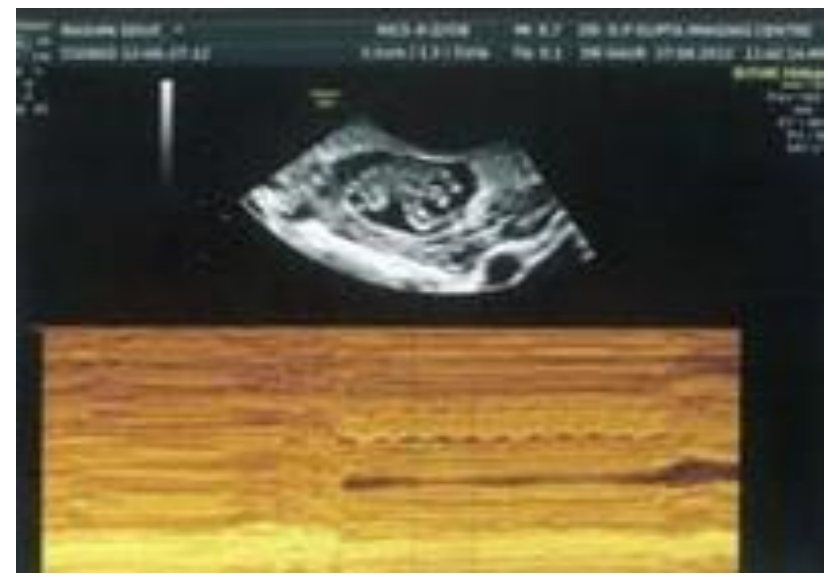

Figure 1: The transvaginal ultrasound illustrating evidence of a gestational sac in the left adnexa adjacent to the left ovary. Careful exploration reveals two embryonic poles.

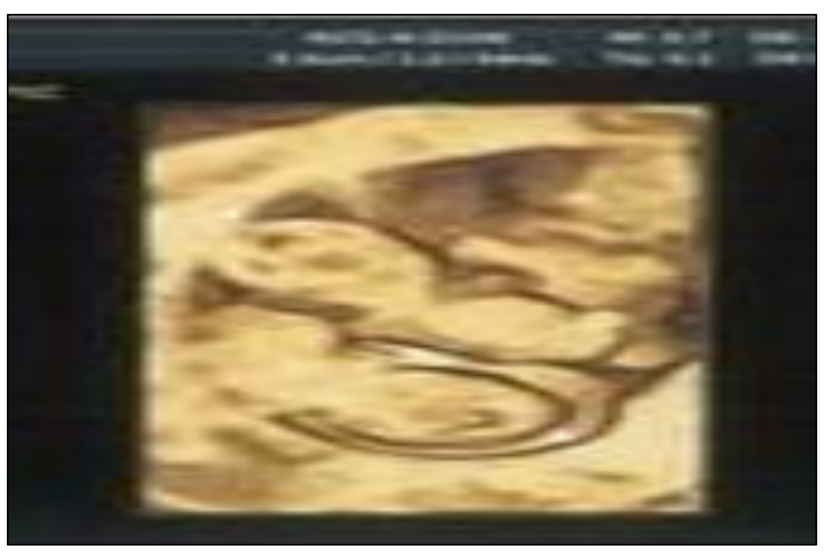

Figure 2: 3D scan of two embryos in a sac.

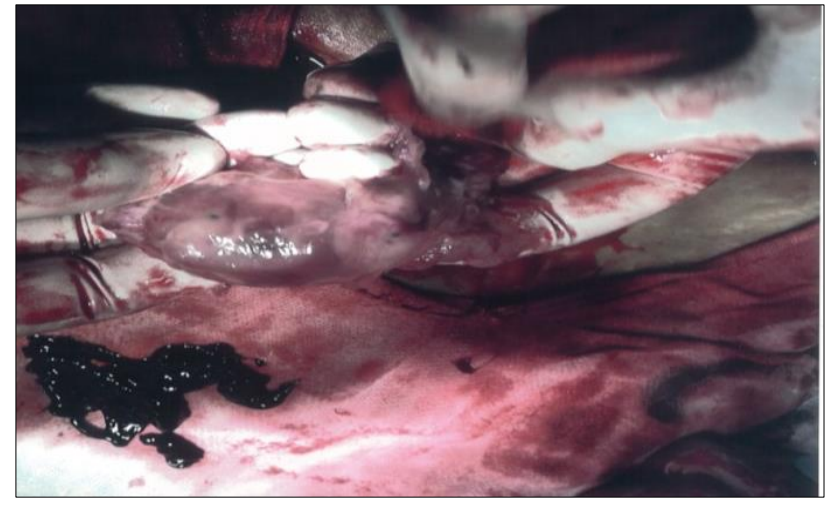

Figure 3: Intraoperative picture showing gestational sac with 2 embryos.

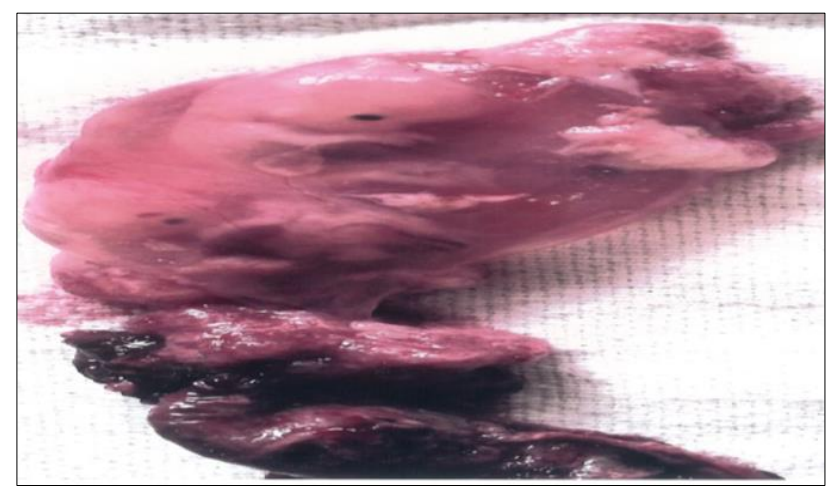

Figure 4: Specimen removed during surgery having left tube with gestational sac with 2 embryos.

\section{DISCUSSION}

Ectopic pregnancies account for $1 \%$ of all pregnancies, represent a major health risk for women of childbearing capacity and can result in life-threatening complications if not treated properly. ${ }^{6,7}$ The classic clinical triad of ectopic pregnancy is pain, amenorrhea and vaginal bleeding. ${ }^{8}$ The incidence of ectopic pregnancies has been increasing since the 1970s. Multiple risk factors which contribute to the incidence of ectopic pregnancy are: pelvic inflammatory disease, previous ectopic pregnancy, history of tubal surgery and conception after tubal ligation, and use of fertility drugs or assisted reproductive technology. Other risk factors include use of an intrauterine contraceptive device, increasing age, smoking and congenital uterine anomalies. ${ }^{7,9}$ Live twin ectopic gestations are extremely rare. The first case of live twin ectopic pregnancy was described in $1994 .^{8}$ Currently, there are approximately 100 published cases in the literature diagnosed pre-operatively and only eight diagnosed cases with documented foetal cardiac activity in a live twin gestation. ${ }^{6,7,10-12}$ A unilateral twin ectopic pregnancy is a rare occurrence which was first described in 1891 by De Ott. Furthermore, a bilateral tubal pregnancy is the rarest form of double-ovum twin pregnancy. ${ }^{7}$ Some studies suggest that there is a delay in ovum transport and consequently implantation, which 
increases the risk of occurrence of monozygotic twin pregnancies. Monochorionic, monoamniotic twin pregnancies will be unilateral. However, if it is dichorionic, diamniotic it may be unilateral but may rarely present as a bilateral ectopic. ${ }^{13}$ Transvaginal ultrasonography has revolutionized the diagnosis of early pregnancy and gynaecological conditions and has become the method of choice for evaluating early pregnancy complications due to its superior resolution. TVUS has changed the approach to the diagnosis of ectopic pregnancy, from being based on the inability to visualize an intrauterine pregnancy to one where a positive diagnosis can be made. TVUS allows visualization of an ectopic mass with or without an embryo within it and detailed evaluation of the adnexa of patients suspected of having ectopic pregnancies. ${ }^{10,14}$ The key to diagnosis of an ectopic pregnancy is determining the presence or absence of an intrauterine gestational sac with correlation of serum B-hCG levels. An ectopic pregnancy should be suspected when TVUS does not show an intrauterine gestation with a serum B-hCG level of $1500 \mathrm{IU} / \mathrm{L}$ or higher. Women with ectopic pregnancies tend to have lower B-hCG levels than those with normal intrauterine pregnancies; however, twin ectopic pregnancies have high levels of $\beta-h C G$ similar to normal intrauterine pregnancies. In this case, the B-hCG level was high (7201 IU/L) at the time of ultrasound examination. The presence of other indirect signs, such as fluid in the Pouch of Douglas, free fluid in the pelvis or a pseudo sac in the endometrial cavity are helpful indicators in establishing the diagnosis. Other presentations could be an in-homogenous adnexal mass or an empty extra uterine sac with an empty endometrial cavity. Other rarer locations for an ectopic pregnancy could be in the cervical region or along the lower anterior segment of the uterine wall with myometrial dehiscence in a ceasarian section scar. ${ }^{15}$ Colour and Pulse Doppler can also help to differentiate a non-specific adnexal mass. The colour flow pattern associated with an ectopic is variable, with a sensitivity of $73-69 \%$ and a specificity of $87-100 \% .^{16,17}$ The colour flow pattern appears as randomly dispersed multiple small vessels showing high velocity and low impedance flow signals (resistive index (RI) of 0.38$0.45)$, the classical ring of fire sign. However, women with tubal abortion demonstrate significantly higher impedance (RI of up to 0.60 ) and less prominent colour flow in the trophoblastic tissue. Therefore, this sign is more likely to be seen in a corpus luteum cyst as this is more common than an ectopic pregnancy. Colour Doppler imaging is most helpful when an ectopic pregnancy is not seen but is highly suspected. In such cases, colour Doppler imaging can be used to help find a mass surrounded by bowel loops. ${ }^{9}$ In this case, colour Doppler and $\mathrm{M}$ mode ultrasound further helped to confirm and document cardiac activity and peritrophoblastic flow. More recently, it has been reported that 3D ultrasound may aid in the management of ectopic pregnancy and it has proven useful in both initial diagnosis and in the follow-up of ectopic pregnancies, especially in assisted reproduction treatment and embryo transfer. ${ }^{12,14,17,18}$ Treatment of an ectopic pregnancy depends on its clinical presentation, size and $\mathrm{B}-\mathrm{hCG}$ levels. It may entail conservative, medical or surgical intervention. Ectopic pregnancies can resolve spontaneously through regression or tubal abortion. Surgical management is reserved for patients who refuse methotrexate or have contraindications to medical treatment and those in whom medical treatment has failed or patients who are haemodynamically unstable. Laparoscopic treatment of ectopic pregnancy is associated with lower cost, less operating time, shorter hospital stays and faster recovery. ${ }^{9,10}$ Salpingectomy is the recommended treatment; however, salpingostomy can be considered for women with one tube who are wishing to preserve their fertility. ${ }^{9}$ With the advancement of ultrasound technology and expertise, and the use of serum B-hCG levels, earlier detection and management of ectopic pregnancy is achieved resulting in an increase in fertility in subsequent pregnancies.

\section{CONCLUSION}

This is a very rare case and urgent exploratory laparotomy with salpingectomy improved the morbidity and mortality of the patient. PID is also among risk factors and may also cause twin ectopic pregnancy.

\section{Funding: No funding sources \\ Conflict of interest: None declared \\ Ethical approval: Not required}

\section{REFERENCES}

1. Bouyer J, Coste J, Fernandez H, Pouly JL, Job-Spira N. Sites of ectopic pregnancy: a 10 year populationbased study of 1800 cases. Hum Repro. 2002; $17: 3224$.

2. Murray $\mathrm{H}$, Baakdah $\mathrm{H}$, Bardell $\mathrm{T}$, Tulandi $\mathrm{T}$. Diagnosis and treatment of ectopic pregnancy. CMAJ. 2005;173:905.

3. Bouyer J, Coste J, Shojaei T, Pouly JL, Fernandez H, Gerbaud L, et al. Risk factors for ectopic pregnancy: a comprehensive analysis based on a large casecontrol, population-based study in France. Am J Epidemiol. 2003; 157:185.

4. Li C, Zhao WH, Zhu Q, Cao SJ, Ping H, Xi X, et al. Risk factors for ectopic pregnancy: a multi-center case-control study. BMC Preg Childbirth. 2015; $15: 187$.

5. Kamwendo F, Forslin L, Bodin L, Danielsson D. Epidemiology of ectopic pregnancy during a 28 year period and the role of pelvic inflammatory disease. Sex Transm Infect. 2000;76:28.

6. Summa B, Meinhold-Heerlein I, Bauerschlag DO, Jonat W, Mettler L, Schollmeyer T. Early detection of a twin tubal pregnancy by Doppler sonography allows fertility conserving laparoscopic surgery. Arch Gynecol Obstet. 2009;279:87-90. 
7. Teresa T, Ali MD, Khazaei MD. Spontaneous unilateral dizygotic twin tubal pregnancy. J Clin Ultrasound. 2009;37:104-6.

8. Ectopic Pregnancy Foundation, Esher, UK. Registered charity no 1122286. Available www.ectopicpregnancy.co.uk. Accessed on 29 September 2014.

9. George M, Nadarajah S, Ong CL. Unilateral twin ectopic pregnancy. JHK Coll Radiol. 2010;12:186-9.

10. Ghike S, Somalwar S, Mitra K. A unilateral twin ectopic pregnancy (Diamniotic-Dichorionic): a rare case. J South Asian Federation Obstet Gynaecol. 2011;3:103-5.

11. Hanchate V, Garg A, Sheth R, Rao J, Jadhav PJ, Karayil D. Transvaginal sonographic diagnosis of live monochorionic twin ectopic pregnancy. J Clin Ultrasound. 2002;30:52-6.

12. Karadeniz RS, Dilbaz S, Ozkan SD. Unilateral twin tubal pregnancy successfully treated with methotrexate. Int J Gynaecol Obstet. 2008;102:1718.

13. Eze JN, Obuna JA, Ejikeme BN. Bilateral tubal ectopic pregnancies: a report of two cases. Ann Afr Med. 2012;11:112-5.

14. Rolle CJ, Wai CY, Bawdon R, Santos-Ramos R, Hoffman B. Unilateral twin ectopic pregnancy in a patient with a history of multiple sexually transmitted infections. Infect Dis Obstet Gynaecol. 2006;2006:10306.

15. Kirk E, Bourne T. Diagnosis of ectopic pregnancy with ultrasound. Best Pract Res Clin Obstetr Gynaecol. 2009;23:501-8.

16. Kupesic S, Kurjac A. Color Doppler assessment of ectopic pregnancy. In: Kurjac A, Kupesic S (eds). An Atlas of Transvaginal Color Doppler. London: Parthenon Publishing; 2000:137-47.

17. Kurjac A, Zalud I, Shulman H. Ectopic pregnancy: transvaginal colour Doppler of trophoblastic flow in questionable adnexa. J Ultrasound Med. 1991;10:685-9.

18. Revicky V, Krishna A, Al-Taher H. Spontaneous monochorionic monoamniotic twin tubal ectopic pregnancy. J Obstet Gynaecol. 2009;29:447.

Cite this article as: Dhama V, Gupta S.

Monochorionic monoamniotic live twin ectopic pregnancy: a rarity. Int J Reprod Contracept Obstet Gynecol 2020;9:828-31. 